\title{
Negotiating Styles in Situation of Limited Resources and Ambiguity: "Short" and "Long" Communications
}

\author{
Svetlana Dzakhotovna Gurieva1*
}

Ulyana Andreyevna Udavikhina²

\author{
${ }^{1}$ Division of Social Psychology, Psychology Department of Saint Petersburg State University, Saint Petersburg, Russia \\ 2 Division of Social Psychology, Psychology Department of Saint Petersburg State University, Saint Petersburg, Russia \\ *Corresponding Author Email: gurievasv@gmail.com
}

\section{Doi:10.5901/mjss.2015.v6n4s2p109}

\section{Abstract}

Success of our cooperation with other people may depend on various factors: whether we have experience in negotiations or not, personal traits of negotiating parties, knowledge and skills in the most effective tactics and strategies of negotiation, ability to understand "body language" of opponents at various levels and in various situations: from game to reality. This article gives test results of business game, which aim was to study balance between verbal and nonverbal communications and styles of negotiations, and how these styles influence the efficiency of negotiation process and results. The results of this research may indicate that observation of verbal and nonverbal channels deepens the negotiation process. In general, it was noticed that in situations of stress and lack of understanding participants mostly preferred "short" communications.

Keywords: negotiations, negotiating styles, "short" and "Iong" communications, verbal and nonverbal means of communication.

\section{Introduction}

\subsection{Introduce the Problem}

Imagine: you have decided to travel around the world. You may perform this in different ways: on feet or by car; by sea liner or by aircraft. Each of you selects your own method and way to achieve your goal. And you certainly do this in your own manner, as you have your own mental coordinate system, based on various values, settings, interests, life experience and knowledge. And in this example we cannot exclude the fact that selection is to be made between comfort and stress, cooperation and solitude. The successful result depends on positive attitude, readiness to get new experience and knowledge on one's way to success, and overcoming various situations of ambiguity, as well as situations of limited material and mental resources. However, the real experience shows that some people can manage this and achieve success, and the others fail. The solution lays in ability to learn, gain new experience and in self-development. Still we can state that, despite of selected method and level of training, it is necessary to set the desired goal, think of how it could be achieved, develop plan of its implementation, and be ready to encounter possible hurdles on the way towards it. To a certain extent, negotiating process resembles travelling (moving) towards the desired goal, where active and positive attitude towards life plays the important role.

Good negotiating skills are considered to be criteria of success in any sphere of our life. And it seems to be reasonable, as negotiations is one of the earliest types of human activity directed to success and prosperity in case of achievement of favorable terms, or to survival in case of conflict management. Negotiation skills are required in all spheres of social cooperation between people: at work place, at home, on vacations, in shop etc (Spangle M.L. \& Isenhart M.W., 2003). And sometimes in all these situations we need to come to an agreement in order to achieve our goals and materialize our interests.

Modern society is a powerful and large-scale flow of information exchange between people. Communication interferes in every sphere of our life, work and recreation. F. Lyutens (1999) suggests for defining main categories of "communication" concept to consider continuum, on one pole of which there is the most complex modern technology of communication, and on the other pole - nonverbal communications.

It could be noted that any change of activity of negotiating parties may be related to increase or decrease of use of nonverbal communications. The use of verbal and nonverbal communications in business games was specially studied by Hauser (Hauser M. et al,. 2002). He stated that language (verbal and nonverbal) performs function of information 
encapsulation. In conditions of limited resources, lack of information and high degree of ambiguity of the situation the players used extremely limited, but intelligible and laconic language of words and gestures. Ambiguity, according to R. Ulmer and M. Kramer, in this case means inability to estimate the present and forecast the future. The reason for this inability lays in shortage of information, level of its complexity or doubts about its quality (Ulmer R.R. et al., 2011, p. 3435; Kramer M.W., 2004, p. 8-9).

On the other words, if negotiating parties prefer collaboration and seek cooperation, does it mean that they will mostly use positive verbal settings, open nonverbal gestures and postures, and support them with positive verbal communications, 'bulging trust' (Solomon R.C. \& Flores F., 2001)? Or, in case they prefer severe competition as negotiating style, will they mostly use negative verbal settings, closed nonverbal postures and gestures, supported by escape from contact and decrease of verbal communications (Coser L.A., 1957; Davis A.M., 1991)?

There are no simple and decisive answers to the above mentioned questions. Still for studying verbal and nonverbal communications method of business games can be successfully used. This method is widely practiced in social and psychological researches, as well as in assessment-centers. Business game simulates the situation which resembles real life situation, in this case - negotiations, and it enables participants of the experiment to forget about observers, who record every their movement and word, and behave naturally. Observing and recording of verbal and nonverbal behavior is the main method of data collection in our research that is supplemented by content analysis and after-experiment survey.

This article gives conditional separation of verbal and nonverbal means of communication to "short" and "long". Using this classification for analysis of negotiating parties' behavior, it is possible to cast a new look at negotiations as a way of information exchange. Additionally, the structure of suggested classification of verbal and nonverbal means of communication is flexible and sensitive to such peculiarities of situation of negotiations as limited resources, stress, and ambiguity. Value of its practical use lays in more precise determination and, possibly, forecast of negotiating style, preferred by participants of business game.

\subsection{Explore Importance of the Problem}

When exploring verbal and nonverbal communications in negotiations, it is required to thoroughly analyze important predictors of their efficiency. We have set a question if there is the most effective style of negotiations, the universal model of successful behavior? The following questions also lay in sphere of research interest: Which criteria can be used to define effective style? Could it be forecast which negotiating style will be selected? Which verbal and nonverbal means of communication are used in the effective negotiating style? The latter question was considered not less important in context of negotiating process, as verbal and nonverbal communications are available for direct studies of interpersonal relations (Allan \& Barbara Pease, 2004, p. 2-30). We should mention that study of modern technologies and universal behavior styles is a point of increased focus of many researchers in various spheres of science (Deaux K., 1987).

\subsection{Describe Relevant Scholarship}

Review of literature enables to state that main attention researchers pay to studies of peculiarities of use of verbal (oral) and nonverbal (non-voice) communications in one or another context. Verbal means of contact are monologues (story, report, lecture etc.) and dialogues (open dialogue and conversation) (llyin E.P., 2011, p. 46-60). Nonverbal means of contact are gestures, facial expressions, actions, objects, as well as codes and symbols.

The main focus of this article is a task to reveal and study "short" and "long" communications in various negotiating styles. The target of research is to study their balance in use of these styles in various situations of negotiating process. Length and content of communications is the subject of research interest, as well as negotiating styles of responders who were the object of this research. During the last century nonverbal communications have been mostly studied, for example, by P. Andersen, M. Argail, K. Floyd, P. Ekman, K. Deaux. On the basis of approach to the study of nonverbal reactions by $A$. Pease, the authors of this article have developed classification of the most common used in negotiating practice universal nonverbal reactions (Table 1): 
Table 1. Nonverbal universal reactions

\begin{tabular}{|l|l|l|l|}
\hline \multicolumn{3}{|c|}{ Voluntary } & \multicolumn{2}{|c|}{ Involuntary } \\
\hline Conscious & Unconscious & Conscious & Unconscious \\
\hline $\begin{array}{l}\text { Postures, movements, } \\
\text { gestures, smile, look, } \\
\text { position in space }\end{array}$ & $\begin{array}{l}\text { Nail-biting, pencil (pen) nibling, leg(s) shaking } \\
\text { or swinging, shuffling of small objects with } \\
\text { fingers, copying posture of the opponent and } \\
\text { others, unconscious at the moment }\end{array}$ & $\begin{array}{l}\text { Blushing, high pulse rate, break of } \\
\text { breathing, nervous trembling, } \\
\text { teeth clenching, teeth grinding, } \\
\text { excessive sweating etc. }\end{array}$ & $\begin{array}{l}\text { Pupils dilation in } \\
\text { reaction to visual } \\
\text { irritating stimulus }\end{array}$ \\
\hline
\end{tabular}

According to Albert Mehrabian and Ray Birdwhistell, more than $65 \%$ of information is transferred by means of nonverbal communication. Communicative unconscious gestures allow "reading" and comprehending state of a person and his attitude to what's happened, which he maybe tried to hide: gestures of incomprehension, ignorance, distrust, perplexity, astonishment, concentration, irony, disgust, suffering, approval, joy, excitement etc.

We have set a question: "Is it possible to forecast and determine negotiating style, used by negotiating parties, by length and content of communication?" In search for the answer to this question we have used the following classification of verbal and nonverbal communications (Table 2):

Table 2. Types of communications used in negotiations

\begin{tabular}{|c|c|c|c|}
\hline \multicolumn{2}{|c|}{ Short communications } & \multicolumn{2}{|c|}{ Long communications } \\
\hline Verbal & Nonverbal & Verbal & Nonverbal \\
\hline $\begin{array}{l}\text { - short phrases (1-3 words), } \\
\text { such as: "No", "Yes", "Well, } \\
\text { no", "We don't know", "Well, } \\
\text { well", "It serves you right", } \\
\text { "We'll see" etc.; } \\
\text { - exclamations, interjections } \\
\text { ("Ah!, Well? Uh huh!") } \\
\text { - imperative verbs ("Let's } \\
\text { start!", "Go", "Keep silence!", } \\
\text { "Finish it!", "Don't ask" etc.). }\end{array}$ & $\begin{array}{l}\text { - quick impulsive gestures (not } \\
\text { more than } 3 \text { seconds): "thumbs } \\
\text { up", "finger put on lips", "come on" } \\
\text { hand gesture, "finger by a temple" } \\
\text { etc. } \\
\text { - short-term changes in } \\
\text { pantomimics and proxemics (not } \\
\text { more than 2-3 seconds): short } \\
\text { glance, harsh body bending, body } \\
\text { twist, springing from seat, back } \\
\text { turn, crossing of hands and legs, } \\
\text { moving away and towards etc. }\end{array}$ & $\begin{array}{l}\text { - presentation (detailed } \\
\text { introduction of oneself, his } \\
\text { team, mission, values, } \\
\text { targets etc.) } \\
\text { - monologue (prolonged } \\
\text { and extended in time story, } \\
\text { description intended to } \\
\text { persuade or prove } \\
\text { something) } \\
\text { - open dialogue (discussion } \\
\text { or information exchange, } \\
\text { equally distributed in time } \\
\text { between participants) } \\
\end{array}$ & $\begin{array}{l}\text { - steady postures (more than } 5 \\
\text { seconds): closed or open } \\
\text { postures } \\
\text { - steady and unchangeable face } \\
\text { expression (more than } 5 \\
\text { seconds): relaxed, intense etc. } \\
\text { - objects shuffling (more than } 5 \\
\text { seconds); } \\
\text { - long-term involuntary gestures } \\
\text { (more than } 5 \text { seconds): covering } \\
\text { mouth with palm, head } \\
\text { scratching etc. }\end{array}$ \\
\hline
\end{tabular}

In the above mentioned classification of communication verbal (linguistic) means of communications had been analyzed, as they having set of clichés and hackneyed phrases, implement strategic and tactic system of negotiations (Lyashenko M.A. \& Maryshova M.A., 2012).

Special attention was paid to gestures, as they are very informative. Ekman and Friesen (Ekman P. \& Friesen W.V., 1969) and David Lewis (2006) define the following types of gestures: adaptive gestures related to cultural specialties of body adaptation to the environment (e.g., shifting in chair during negotiations), symbolic gestures actively used to confirm what was said ("OK" symbol that means that everything is "all right"), illustrative gestures used to clear what was said (confirming nods or negative headshakes) and regulatory gestures (handshake, business cards exchange).

\subsection{State Hypotheses and Their Correspondence to Research Design}

The above suggested division of verbal and nonverbal communication into "short" and "long" may serve as a precise tool for observation and careful analysis of negotiation process content. Besides, this classification allows making a set of assumptions, such as:

1) at high rate of stress within a team and between the teams verbal and nonverbal communications may be significantly shortened in time with increase of their frequency. On the other words, in situations of incomprehension and stress negotiating parties may prefer to use "short" communications in order to reduce stress and increase mutual understanding by using maximum informative means of contact.

2) "short" verbal communications may be predominantly used in situations of stress when time for making 
decision is strictly limited and in situations of frustration when negotiating parties fail to come to mutual agreement.

3) "Long" verbal communications may be primarily used by parties when they have possibility to share their opinion, to describe advantages of their strategy. By using "long" verbal communications negotiating parties demonstrate their interest, try to obtain additional clarifying information, to clear up position of the other party.

In order to check the above mentioned hypotheses in our research we have matched generalized data from supervisors' observing forms, where all demonstrations of verbal and nonverbal communications, divided into "short" and "long" ones, were recorded, and negotiating style, selected by participants of business game (recorded in special forms and implemented in course of the experiment).

It was supposed, that negotiating style may depend on such personal traits, as level of propensity to conflict, aggressiveness, resistance to stress, propensity for manipulations. Manipulations in this case mean "type of psychological impact, subtle performance of which inwardly agitates intentions in other person that do not coincide with his actual wishes" (Dotsenko E.L., 1997, p. 58-59). The above mentioned personal traits of participants of the research were determined by after-experiment questionnaires: "Personal aggression and propensity to conflict" methodology by $\mathrm{E}$. P. Ilyin and P. A. Kovalev, and "Machiavellianism" Scale (Bratchenko S.L., 1997).

\section{Method}

The research was performed in the form of business game, which was supposed to include random distribution of participants between teams, performance of determined challenge, achievement of set goal, assessment of the result and feedback from participants of the game. Besides after the game participants were asked to fill in several tests and questionnaires intended to reveal some of their personal traits.

\subsection{Participant Characteristics}

The sampling consisted of 30 students of Saint Petersburg State University who have not yet graduated. Their average age was 20.38 years $(\delta=1.15)$. Gender composition: women $-62.5 \%$, men $-37.5 \%$ correspondingly. It was supposed that rare students have sheer experience in conducting business negotiations and are professionals in changing negotiating style depending on situation. That is why we invited everyone who desired to practice their negotiating skills.

\subsection{Sampling Procedures}

The research involved on voluntary basis everyone who was interested among students of Saint Petersburg State University. Each participant, after reading and signing the informed consent for participation, gained opportunity to learn the goal, tasks and procedure of the research, and to withdraw from the experiment at any time. The business game was conducted on the base of Psychology Department of Saint Petersburg State University. As the form of business game assumed division of participants of the experiment into teams, we found it reasonable to form teams of 5 to 10 people, and provide 1 or 2 supervisors for each team.

\subsection{Measures}

Use of verbal and nonverbal means of contact was recorded by the supervisors in the observing form, and further, during content analysis of after-experiment questionnaires, was matched with selected negotiating style (Fisher R. et al., 2013, p. 19-33).

Participants of the research were divided into three teams, and each team received box with jigsaw puzzle and the form to put selected strategy and tactics in. The jigsaw puzzles represented both mind challenge to be solved by the participants and quantitative index of successful accomplishment of group challenge.

In order to ease cooperation between participants each team also received money equivalent to the puzzle pieces in form of game coins that could be exchanged to the puzzle pieces and back.

After termination of the business game each participant was asked to fill in the following forms: 1) "Behavior description test by K. Thomas" in order to determine mostly preferable negotiating style (competing, collaborating, compromising, avoiding, accommodating); 2) a questionnaire, developed by authors of the article, that is based on classification of approaches to negotiations suggested by R. Fisher and W. Ury (hard, soft and principled approaches); 3 ) "Machiavellianism" Scale for determination of propensity to manipulate. 
Supervisors, engaged in arrangement of the business game, received preliminary information about "short" and "long" communications model, developed by authors of the research, and were instructed on how to fill the observing forms in.

\subsection{Instruction}

Prior to the game start the teams were instructed on the following: "Your main challenge is to collect as much puzzle pieces for your picture as possible, still saving as much money as possible. You may use game coins to perform recourses exchange operations. Within teams analyze the current situation and currently available problems, then think of strategy of your actions and develop tactics that may be used on the basis of the selected strategy".

"Berlin" and "Barcelona" teams followed "Win-Win" strategy (Covey S., 2013), and "Havana" team selected "WinLose" as their strategy. In the course of the game members of the teams, acting in accordance with challenge of the business game, used different negotiating tactics, such as: manipulations, threats, retreat, separation principle, gradual increase of complexity of the discussed questions etc.

\subsection{Procedure}

Authors of the research have tested «Buzzle-Puzzle» (original author's name) business game (Gurieva S.D. \& Udavikhina U.A., 2014a). Its main task, conceived during the research, is the following: which behavior traits of a person, social and psychology factors influence preference of the strategies and tactics for negotiations and may influence success of the activity (in this case - activity in team). To perform the task participants of the research were divided into three teams, conditionally named as "Berlin", "Barcelona" and "Havana".

Each team was asked to assemble a jigsaw puzzle out of pieces in the box. So, one team assembled "Barcelona"picture, the other team - "Berlin" picture, and the third team - "Havana" picture. The challenge was complicated by mixing of all puzzle pieces from three boxes and uneven distribution between the teams. It was made in order to approximate game conditions to real circumstances of business environment: a) resources are distributed between groups (participants, organizations, countries) unevenly, which may appear to be potential for conflict communication between participants of the game; b) the teams were interdependent as each team possessed the excessive resource, which was required by other teams (puzzle pieces that matched other pictures); $c$ ) each team was to start with determination of what resource they need, find the missing resource among resources of the other team and agree on conditions of acquisition of this missing resource (puzzle pieces). The game format also implied roles division within the team. The following roles were assigned by random selection: "negotiator" (priority right and obligation to conduct negotiations with other teams), "cash keeper" (accounting of team's income and expenditures), "collector" (use of resource by means of its transformation) and "observer" (observe the participants and record their behavior in observing form).

The business game had 4 stages, during which the experiment conductor and observers recorded verbal and nonverbal communications of participants of the research. Each stage was strictly limited in time.

Main stages of the game:

1) Preparatory stage. The basic task for the teams: preparation of presentation of the team, selection of strategy and tactics, instruction, materials handout, distribution of roles;

2) Information exchange. The basic task: operation in team to perform the challenge, data exchange, development of actions program;

3) Achievement of agreement. The basic task: resources exchange, concessions, intermediate summary;

4) Final stage. The basic task: analysis of negotiation results, summary of the game, feedback.

\section{Results}

In the course of research according to observation forms the following specialties of verbal and nonverbal communications between participants were revealed (see Table 3): 
Table 3. Communications during negotiations at different stages

\begin{tabular}{|c|c|c|c|c|}
\hline \multirow[t]{3}{*}{ Stage of negotiations } & \multicolumn{4}{|c|}{ Communications } \\
\hline & \multicolumn{2}{|r|}{ Short } & \multicolumn{2}{|l|}{ Long } \\
\hline & Verbal & Nonverbal & Verbal & Nonverbal \\
\hline $\begin{array}{l}\text { 1.Preparatory stage } \\
\text {-Instruction } \\
\text {-Materials handout } \\
\text {-Distribution of roles } \\
\text {-Selection of strategy }\end{array}$ & $\begin{array}{l}\text { Questions on instruction } \\
\text { ("What does this mean?"), } \\
\text { exclamations, commands } \\
\text { ("You will be the collector!", } \\
\text { "Does everyone understand?", } \\
\text { "Who has questions?") }\end{array}$ & $\begin{array}{l}\text { Quick exchange of looks between } \\
\text { participants within team, hand rise to } \\
\text { ask a question }\end{array}$ & $\begin{array}{l}\text { Discussion of received materials, } \\
\text { distribution of roles, selection of } \\
\text { strategy, specification of details and } \\
\text { conditions of the game. }\end{array}$ & $\begin{array}{l}\text { Detached look out of } \\
\text { window, leg swinging, CP } \\
\text { and OP } 1 \text {, running fingers } \\
\text { through elements of } \\
\text { clothing and hair. }\end{array}$ \\
\hline $\begin{array}{l}\text { 2. Information exchange } \\
\text { - Operation in team } \\
\text { - Data exchange } \\
\text { - Development of actions } \\
\text { program }\end{array}$ & $\begin{array}{l}\text { Indignant exclamations, } \\
\text { attacks ("Stay away!", "Hide it", } \\
\text { "Don't show them", "We have } \\
\text { no idea", "Don't talk to them", } \\
\text { "Maybe", "We'll see") }\end{array}$ & $\begin{array}{l}\text { Sway of arm intended to repel a } \\
\text { participant out of the table, head } \\
\text { shakes that mean disagreement or } \\
\text { refusal, quick change of look without } \\
\text { answering to the interlocutor, glance } \\
\text { exchanges and eyewinking between } \\
\text { members of one team }\end{array}$ & $\begin{array}{l}\text { Discussion of course of the game, } \\
\text { questions and requests to the } \\
\text { experiment conductor, free dialog } \\
\text { between teams' negotiators ("Let's } \\
\text { discuss our and your suggestions", } \\
\text { "Could you be so kind to explain why?", } \\
\text { "If we agree..., then you will agree..." } \\
\text { etc.). }\end{array}$ & $\begin{array}{l}\mathrm{OP}, \mathrm{CP} \text { are predominant, } \\
\text { active hands gestures, } \\
\text { postures of interest and } \\
\text { (body bending forward) }\end{array}$ \\
\hline $\begin{array}{l}\text { 3. Achievement of agreement } \\
\text { - Operation in team } \\
\text { - Resources exchange } \\
\text { - Concessions } \\
\text { - Intermediate summary }\end{array}$ & $\begin{array}{l}\text { Exclamations ("I got it!", "How } \\
\text { come?"), laugh, commands } \\
\text { ("Check number of puzzle } \\
\text { pieces") }\end{array}$ & $\begin{array}{l}\text { Head nods, scratching of face and } \\
\text { head, amazed face expression }\end{array}$ & $\begin{array}{l}\text { Dialogues between members of teams, } \\
\text { monologues of negotiators in the } \\
\text { course of negotiations }\end{array}$ & $\begin{array}{l}\text { Active gestures, OP and } \\
\mathrm{CP} \text {, covering mouth with } \\
\text { palm when speaking, } \\
\text { pencil shuffling in hand }\end{array}$ \\
\hline $\begin{array}{l}\text { 4. Final stage } \\
\text { - Analysis of negotiations results } \\
\text { - Summary of the game } \\
\text { - Feedback }\end{array}$ & $\begin{array}{l}\text { Exclamations, short phrases } \\
\text { ("We're winners!", "It's not fair") }\end{array}$ & $\begin{array}{l}\text { Expression of astonishment, joy, grief } \\
\text { (depending on outcome of the team } \\
\text { game) }\end{array}$ & $\begin{array}{l}\text { Monologues of participants, dialogue } \\
\text { with experiment conductor, discussion } \\
\text { of the game results }\end{array}$ & $\begin{array}{l}\mathrm{CP} \text { and OP, posture of } \\
\text { critical assessment, } \\
\text { tapping fingers on the } \\
\text { table, legs shaking }\end{array}$ \\
\hline
\end{tabular}

The observers defined level of activity of participants of the research both within the teams and in cooperation with other teams. In order to perform this, the special observing sheets were developed, where it was recorded the following: a) activity within the team - by quantitative index of performance of group challenge (number of points for the assembled elements of the jigsaw puzzle), b) activity between the teams - by number of conducted negotiations and contacts between representatives of different commands.

In addition, content analysis of game materials together with observations allowed determining selection of the negotiating strategy and approach to negotiations used by participants in the course of experiment.

\subsection{Results analysis}

The above mentioned results of measurements and observations are given in Table 4.

Table 4. Results of measurements in the course of the research

\begin{tabular}{|l|l|l|l|}
\hline The observed characteristic & "Berlin" & "Barcelona" & "Havana" \\
\hline Level of activity within the team & Medium & Medium & High \\
\hline Level of activity between the teams & High & Medium & High \\
\hline Negotiating strategy & Win-Win, Lose-Lose & Win-Win & Win-Lose \\
\hline Preferable approach to negotiations & Principled & Principled & Principled \\
\hline Actually used approach to negotiations & Hard & Principled & Hard \\
\hline Negotiating style (according to K. Thomas) & $\begin{array}{l}\text { Compromising (mean value 6.75), } \\
\text { avoiding (mean value 6.75) }\end{array}$ & $\begin{array}{l}\text { Compromising } \\
\text { (mean value 7.00) }\end{array}$ & $\begin{array}{l}\text { Compromising } \\
\text { (mean value 8.43) }\end{array}$ \\
\hline Use of manipulation and propensity to it & $\begin{array}{l}\text { Was observed; } \\
\text { propensity 62\% }\end{array}$ & $\begin{array}{l}\text { Was not observed; } \\
\text { propensity 56\% }\end{array}$ & $\begin{array}{l}\text { Was observed; } \\
\text { propensity 54\% }\end{array}$ \\
\hline Intermediate summary of the game & 39 points & 35 points & 21 points \\
\hline Final summary of the game & 94 points & 131 points & 150 points \\
\hline
\end{tabular}

So, the result appeared to be quite unexpected: "Berlin" team, which was a strong leader in gained points in intermediate summary, lost the game with huge gap in points with other teams! To understand what factors influenced such outcome of the game we have analyzed specialties of each team.

\section{"Berlin" team}

1) its members showed medium degree of activity within the team (i.e. each member of the team was involved in

${ }^{*} \mathrm{CP}$ and OP (hereinafter) - closed posture, open posture. 
performance of group challenge both individually (by sorting and matching puzzle pieces) and in cooperation with other members of the team);

2) members of the team were involved in active contact with other teams: took initiative during negotiations, eagerly started dialogs with members of other teams;

3) has initially selected "Win-Win" strategy (as it was indicated in special form prior to the game start); according to indicators of "Behavior description" test by $\mathrm{K}$. Thomas, the preferable negotiating styles were compromising and avoiding; and intention to stick to the principled approach was openly declared. Still, according to $\mathrm{MACH}$ scale, members of the team showed propensity to consider it possible to use manipulations, and used them in the course of the game;

4) in the end of the game members of the team confessed that, being under high pressure of "Havana" team, they tried everything possible to prevent winning of this team: used pressure, deceit, manipulations and threats (that is the mark of hard approach to negotiations). On the other words, they have changed preliminary selected "Win-Win" strategy to the "Lose-Lose" one.

"Barcelona" team

1) similar to "Berlin" team, its members showed medium degree of activity within the team (i.e. each member of the team was involved in performance of group challenge both individually (by sorting and matching puzzle pieces) and in cooperation with other members of the team);

2) showed medium activity in contact with other teams (i.e. members of the team were involved in cooperation with other teams only on the basis of necessity and rarely took initiative in the course of the game);

3) has initially selected "Win-Win" strategy; the preferable negotiating style was compromising; and intention to stick to the principled approach was openly declared. The team followed this principle in the course of the game, and did not use manipulations (though its members had propensity to manipulations almost equal to other teams).

"Havana" team

1) its members showed high degree of activity within the team (there was clear distribution of roles within the team, members of the team coordinated their actions internally and regularly asked for advice from the team leader);

2) members of the team were involved in active cooperation with other teams: took initiative during negotiations, eagerly started dialogs with members of other teams;

3) has initially selected "Win-Lose" strategy and in the course of the game showed hard approach with use of pressure, threats, "runarounds", retreat, making steep demands, manipulations and other tactics, typical to this approach.

\section{Discussion}

In the course of experiment closed postures were revealed to prevail during negotiations between teams. Verbal and nonverbal demonstrations of agitation and discontent (exclamations, closed postures, tapping fingers on the table, legs shaking) were predominantly shown by "Berlin" team, which was under pressure of the leader of "Havana" team, who used energetic gestures, moved around table of the opponents, changed voice tone, and used swear words. Generally it was noticed that in conditions of high index of stress both within a team and between the teams, verbal and nonverbal communications were significantly shortened in time, and frequency of their use increased. On the other words, in situation of incomprehension and stress the participants predominantly used "short" communications that may be explained by tendency to reduce stress and increase mutual understanding by using maximum informative means of contact.

It is interesting to note the fact that in summary of the business game "Havana" team scored the most points by sticking to "Win-Lose" strategy, while the former leader - "Berlin" team, which has changed "Win-Win" strategy to "WinLose" strategy under pressure from "Havana" team, scored the least points.

Obviously, this does not mean that "Win-Win" strategy, which is postulated in literature as the most effective for negotiating process, is actually unsuccessful. The purpose of our research was different: We aimed to search those specialties of verbal and nonverbal communication, which may signal of preference of one or the other negotiating style and approach prior to start negotiating process. On our opinion, we have managed to trace them by matching characteristics of situation of negotiations and specialties of verbal and nonverbal communications of participants in the course of the game. 


\section{General Discussion}

It is worth to mention that "short" verbal communications were mainly used in stress situations when time for performing the challenge was strictly limited, and in situations of frustration, when participants failed to come to mutual agreement, or when they some way disturbed each other during performance of challenge. Short brisk phrases were predominantly used in the situations when teams did not intend to meet halfway and, on the opposite, boosted confrontation and increased stress. In these short verbal communications it was possible to "read" reluctance to open cooperation and demonstrations of suspiciousness and isolation (Gurieva S.D. \& Udavikhina U.A., 2014b). It was especially evident when verbal phrases were accompanied by nonverbal closed gestures, which emphasized what was said and cleared up dominating emotions of participants of the experiment.

"Long" verbal communications were mainly used by participants in the cases when they had possibility to share their opinion, speak out arguments in favor of their strategy. With "long" verbal communications the participants demonstrated their interest, tried to receive additional clarifying information and to clear up position of the other party. In case they were not interested in what was happening in the course of business game, they tried to explain why it is so. It is important to mention that openness for contact, intention to find mutual interests and positions is considered as a key to successful business contact (Vetrenko I.A., 2009).

Short and long verbal communications may be regarded as special communicative contact codes, which in one situation may demonstrate confrontation, stress, friction and non-acceptance, and in the other mean willingness, eagerness, intention for cooperation and constructive dialog. It is worth mention that they are most vividly demonstrated at the stage of information exchange, in situation when ambiguity, lack of time and unevenness of distribution of resources were evident.

Besides, on the basis of the proposed communication model it is possible to perform the research of gender differences in use of verbal and nonverbal communications. It was noted that women tell lies more often when providing information, which causes dissonance in content of verbal and demonstration of nonverbal components and may lead to more extended in time long communicative reactions. Men may prefer to keep silence and take meaningful pause in discussion, showing prompt and informative signals. Still the above mentioned notes and comments are specific to the situation, although they were recorded by all observers and supervisors.

Among the other, the test results of «Buzzle-Puzzle» business game may witness that selection of different strategies and tactics may lead to different outcomes in conflict resolution.

\subsection{Limitation, future research, and implications}

An analysis of the literature on negotiations included the verbal and nonverbal communication was made in this paper. Based on this, firstly, a new classification of types of communications in the negotiations was introduced. Secondly, it was found obviously in the experimental conditions that in situations of tension and uncertainty of the participants, who preferred aggressive and active style of Win-Lose or aggressive-passive style Lose-Lose, demonstrated a significant reduction in time both as verbal as non-verbal communications. Thirdly, the "long-term" verbal communication in a situation of limited time and the uncertainty managed to relate to the constructive behavior of decision of the talks that we would think that it is the key to finding the more successful negotiation style.

Study of verbal and nonverbal communications in the course of negotiations contribute both search of the most effective behavior model in negotiating practice and definition of social and psychological conditions that influence achievement of mutually beneficial results, quality of operation and terms of fulfillment of the set challenge. Researches in the field of social psychology and management psychology allow expanding horizons of scientific investigations related to negotiating process. In this study we have first time developed and tested the business game, which conditions were highly approximated to the real conditions of negotiations and could significantly influence the outcome of negotiating process and result. It is worth to mention that use of business game for studying many aspects of negotiating process is believed to be a perspective direction for scientific researches in the field of psychology. In prospect we plan to identify the procedure of agreement achievement in negotiations.

As in study, the methods used produced some possible limitations, as well several interesting directions for future research. The current study utilized a new classification of communications used in negotiations based on a hypothetical time division. This strategy allowed for the control of a number of extraneous variables, including the unconscious behavior not involved in negotiation process, and many more that may have founded by tests. Nevertheless, business game is a hypothetical scenario that may not adequately reflect all the realities of actual negotiating. At the same time, focusing on the results of studies using this method, we expect that the present results will likely open a new way to 
explore negotiation. Although, as in all laboratory experiments, our method triggers some questions of generality and potential boundary conditions. Nevertheless, future research is necessary to explore how study of verbal and nonverbal communications in the course of negotiations contribute both search of the most effective behavior model in negotiating practice. Moreover, though the verbal-nonverbal communication literature has not systematically studied in negotiation context by researches, our results strongly suggest that it should.

\section{References}

Bratchenko S.L. (1997) Diagnosis propensity to manipulate. In S.L. Bratchenko (Ed.), Diagnosis of personality-developing potential: handbook for school psychologists (pp. 56-62). Pskov: Pskov Regional Institute of Training and Education Publ.

Coser, L.A. (1957). Social conflict and change. British Journal of Sociology, 8(3), 197-217.

Covey S. (2013) The Seven Habits of Highly Effective People. New York: Simon \& Schuster.

Davis, A.M. (1991). Follett and facts: Timely advice. Negotiation Journal, 7(2), 131-138.

Deaux, K. (1987). Putting gender into context: An attractive model of gender-related behavior. Psychological review, 94 (3), 369-389.

Dotsenko E.L. (1997) Psychology of Manipulation: Phenomena, Mechanisms and Protection. Moscow: CheRo, Moscow State University Publ.

Ekman P. \& Friesen W.V. (1969) The Repertoire of Nonverbal Behavior: Categories, Origins, Usage, and Coding. Semiotica, 1: 49-98.

Fisher R., Ury W. \& Patton B. (2013) Negotiations Without Defeat. Harvard Method (2nd ed.) Moscow: Mann, Ivanov and Ferber.

Gurieva S.D. \& Udavikhina U.A. (2014a) Business Game as an Instrument of the Study the Styles of Negotiations. In Mazilescu V. (Ed.), Proceedings of the 2nd European Conference on Education and Applied Psychology (pp. 284-292). Vienna.

Gurieva S.D. \& Udavikhina U.A. (2014b) Preservare e mantenere relazioni di fiducia in una situazione di interazione tra gruppi Italian Science Review, 21 (12): 69-73. http://www.ias-journal.org/archive/2014/december/Gurieva.pdf

Hauser M., Chomsky N. \& Fitch W.T. (2002) The Faculty of Language: What Is It, Who Has IT, and How Did It Evolve? Science, 298: 1569-1579. http://www.chomsky.info/articles/20021122.pdf

Ilyin E.P. (2011) Psychology of Communication and Interpersonal Relations. St. Petersburg: Piter.

Kramer M.W. (2004) Managing uncertainty in organizational communication. Mahwah, NJ: Lawrence Erlbaum Associates.

Lewis D. (2006) Language of Effective Communication. Moscow: Eksmo.

Lyashenko M.A. \& Maryshova M.A. (2012) Linguistic and stylistic features of the negotiation process as a phenomenon of business communication. Herald of the Siberian Institute of Business and Information Technology, 4: 71-72. http://elibrary.ru/download/ 60880105.pdf

Lyutens F. (1999) Organizational Behavior. Moscow: INFRA-M.

Pease A. \& Pease B. (2004) The Definitive Book of Body Language. Australia: Pease International. http://e-edu.nbu.bg/pluginfile.php/ 331752/mod_resource/content/O/Allan_and_Barbara_Pease_-_Body_Language_The_Definitive_Book.pdf

Solomon, R.C., Flores F. (2001). Bulging trust. Oxford: Oxford University Press. http://global.oup.com/

Spangle, M.L., Isenhart M.W. (2003). Negotiation. Thousand Oaks, London, New Delhi: Sage Publications.

Ulmer R.R., Sellnow T.L. \& Seeger M.W. (2011) Effective Crisis Communication. Kharkiv: Humanitarian Center Publ.

Vetrenko I.A. (2009) Game approach to political negotiations. Ural Federal University News, 4: 166-170. http://elibrary.ru/download/733 74307.pdf 